\title{
Do karst woody plants control xylem tension to avoid substantial xylem cavitation in the wet season?
}

\author{
Dayong Fan ${ }^{1^{*}} \mathbb{D}$, Shouren Zhang ${ }^{2^{*}}$, Hui Yan ${ }^{2,3}$, Qian $\mathrm{Wu}^{2}$, Xinwu Xu ${ }^{2,4}$ and Xiangping Wang ${ }^{1}$
}

\begin{abstract}
Background: Plants have been hypothesized to maintain strong control over xylem tension by closing stomata and to operate at a water potential above or near the critical potential at which cavitation commences. An alternative hypothesis holds that cavitation temporarily relieves water stress and stomatal closure is insufficient to prevent short term "run-away" cavitation.
\end{abstract}

Methods: The objectives of this study were to investigate the leaf conductivity loss at noon (Loss) of 13 woody species differing in leaf phenology at two sites on karst topography in the wet season in southwestern China; the hydraulic architecture of woody species has rarely been reported previously. Loss was predicted from minimum field leaf water potentials $\left(\Psi_{\mathrm{min}}\right)$ and laboratory-generated vulnerability curves. We also measured the maximum quantum efficiency of photosystem $\mathrm{I}$ using chlorophyll a fluorescence $\left(F_{\mathrm{v}} / F_{\mathrm{m}}\right)$ and other associated leaf traits.

Results: Loss in the field varied substantially, from 1.39\% in evergreen Itea chinensis to $90.07 \%$ in deciduous Sapium sebiferum. However, the Loss did not significantly decrease the efficiency of photosystem II. The water potential at which a $50 \%$ loss in leaf conductivity occurred $\left(\psi_{50}\right)$ was not correlated to $\psi_{\mathrm{min}}$. The co-occurring evergreen and deciduous species differed significantly in some stem hydraulic and associated leaf traits. Deciduous species had higher hydraulic conductance, photosynthetic rate, stomatal conductance, lower cavitation-resistance and minimum water potential than co-occurring evergreen species.

Conclusions: There was no sign that karst woody species in southwestern China could control xylem tension above the threshold to avoid substantial xylem cavitation in the wet season. There was no association between Loss and $F_{\mathrm{v}} / F_{\mathrm{m}}$ among the studied species. This "isohydric" regulation behaviour, as well as abundant rainfall in the wet season, may explain why large variations of Loss existed across karst woody species in southwestern China.

Keywords: Karst forest, Leaf conductivity loss, Leaf phenology, Photochemistry efficiency of photosystem II

\section{Introduction}

Cavitation-induced decrease in the hydraulic conductance of plant stems, roots, and leaves has long been suggested to lead to stomatal closure, thereby preventing the increase in xylem tension that can induce run-away xylem cavitation (Jones and Sutherland 1991; Nardini and Salleo 2000; Domec et al. 2006; Guyot et al. 2012; Daniela et al. 2016; Xiong et al. 2018). Because embolized xylem cells can reduce hydraulic conductivity and

\footnotetext{
* Correspondence: dayong.fan@anu.edu.au; zsr@ibcas.ac.cn

${ }^{1}$ College of Forestry, Beijing Forestry University, Beijing 100083, China

${ }^{2}$ State Key Laboratory of Vegetation and Environmental Change, Institute of

Botany, Chinese Academy of Sciences, Beijing 100093, China

Full list of author information is available at the end of the article
}

greatly retard photosynthesis and growth, plants would be expected to have strong control over xylem tension and typically operate at a water potential above or near the critical potential at which cavitation commences (Sperry 2000). This hypothesis has been evidenced by tight associations between minimum water potential and hydraulic resistance in various ecosystems (e.g., Pockman and Sperry 2000; Markesteijn et al. 2011b; Gadow et al. 2016). For instance, Nardini and Salleo (2000) demonstrated that 11 tree species in a Mediterranean ecosystem suffered an average of $10 \%$ cavitation before stomata began to close. A survey of the hydraulic architecture of 13 tropical dry forest species in Bolivia showed that the 
average loss of hydraulic conductivity corresponding to minimum leaf water potential was about $20 \%$ in the wet season (Markesteijn et al. 2011b).

However, the functional association between minimum water potential and hydraulic safety does not prove that plants can control embolisms, because the loss of hydraulic conductivity is not a linear function of water potential. In fact, a detailed analysis of published data has shown that there exists a large variation among species at the same site in native embolism rates during a day (Pockman and Sperry 2000; Markesteijn et al. 2011a, 2011b). For example, re-analysis of data from Markesteijn et al. (2011a, 2011b) revealed that daily conductivity loss ranged from $5 \%-63 \%$ of maximum conductivity. The embolism rate varied widely, from $11 \%-95 \%$ in the dry season and from $11 \%-93 \%$ in the wet season, across 12 Sonoran desert species (Pockman and Sperry 2000).

Johnson et al. (2009) hypothesized that there may exist two different strategies for the daily maintenance of hydraulic conductivity: 1) a "radical" strategy of substantial loss and subsequent recovery and 2) a more conservative strategy of loss avoidance. Such a hypothesis, we believe, should be assessed broadly in different global ecosystems for a more comprehensive understanding of the role of cavitation in plant water balance. Furthermore, the two strategies might have different impacts on photosynthesis. The conservative strategy requires that plants close their stomata before catastrophic hydraulic failure occurs. As soon as stomata close, photosynthesis would suffer from a shortage of $\mathrm{CO}_{2}$ and absorbed light would exceed photosynthetic requirements; consequently, photosystem II (PSII) would be temporarily or chronically photo-inactivated, which could be reflected by a decrease in maximum quantum efficiency of PSII photochemistry $\left(F_{\mathrm{v}} / F_{\mathrm{m}}\right)$ (Baker 2008). On the other hand, the radical strategy, which allows massive temporary cavitation with stomata open, would not affect PSII photochemistry, because ambient $\mathrm{CO}_{2}$ could diffuse into leaf intercellular spaces, particularly if such massive cavitation temporarily relieved water stress (Holtta et al. 2012); therefore its $F_{\mathrm{v}} / F_{\mathrm{m}}$ should be higher than that in the conservative strategy. This expectation, to our knowledge, has not yet been tested.

The karst topography is characterized by shallow soils with low water-retention capacity and high porosity of the underlying limestone rock. Compared to other karst areas at similar latitudes, the karst area in southwestern China is unique because of its abundant precipitation, with rainfall concentrated in the growing season (from May to September) (Wu et al. 2003), mainly due to the rise in elevation of the Qinghai-Tibet Plateau. Previous studies have shown that the water potential at which a $50 \%$ loss in hydraulic conductivity occurs $\left(\Psi_{50}\right)$ in 31 woody species in this area was only $-1.27 \mathrm{MPa}$ (Fan et al. 2011), compared with high resistance in Mediterranean (Tognetti et al. 1998) and Central American karst regions (McElrone et al. 2004). Xylem tension measurements in the wet season have shown that woody plants experienced average midday leaf water potentials $\left(\Psi_{\text {min }}\right)$ of about - 1.5 MPa (Yu et al. 2002; Liu et al. 2012), suggesting that, on average, more than $50 \%$ embolism will occur in the field. Unfortunately, the $\Psi_{50}$ and $\Psi_{\min }$ measurements were made either separately or across different species; therefore, whether karst woody plants in southwestern China can control xylem tension above a critical threshold remains unknown. This knowledge is also crucial to better evaluate the suitability of plant species to site-specific reforestation programs in the karst area in southwestern China, which has suffered serious degradation due to intensive human disturbances.

The objectives of present study were to 1) investigate variation in native embolism in branches and its relationship to leaf traits in 13 woody species (six evergreen and seven deciduous) at two sites in the karst area of southwestern China; 2) examine whether there are associations between Loss and PSII's photochemistry among woody species; and 3) investigate the relationship between native embolism and leaf phenology. Because many studies have demonstrated that evergreen species have larger safety margins (the difference between $\Psi_{\text {min }}$ and the water potential at which cavitation occurs), higher cavitation resistance, and lower daily minimum water potential (Choat et al. 2005; Chen et al. 2009; Markesteijn et al. 2011b; O'Brien et al. 2017) than co-occurring deciduous species, we expected that evergreen species would lose less conductivity than deciduous species on sunny days.

\section{Materials and methods Study area}

The study was conducted at two sites in Guizhou Province, southwest China. The Huajiang site $\left(\mathrm{HJ} ; 25^{\circ} 42^{\prime} \mathrm{N}\right.$, $105^{\circ} 35^{\prime} \mathrm{E}, 900 \mathrm{~m}$ a.s.l.) and the Puding site (PD; $26^{\circ} 15^{\prime} \mathrm{N}$, $105^{\circ} 44^{\prime} \mathrm{E}, 1200 \mathrm{~m}$ a.s.l.). The two sites were $60 \mathrm{~km}$ from each other, in the southwestern and western parts of the province and have mean annual temperatures $18.4^{\circ} \mathrm{C}$ and $15.1^{\circ} \mathrm{C}$, respectively. Both sites have very few days with temperatures below $0{ }^{\circ} \mathrm{C}$ in winter (Wu et al. 2003).

The Huajiang site has a warm temperate climate, with a mean annual precipitation (MAP) of $1100 \mathrm{~mm}, 83 \%$ of which occurs during the growth season between May and October. Vegetation in this region is characterized by sparsely distributed secondary deciduous trees and shrubs on bare rocks. The Puding site is dominated by a humid monsoon climate. The MAP is $1398 \mathrm{~mm}, 60 \%-$ $70 \%$ of which occurs between May and October. The Puding site has a well-developed secondary evergreen 
and deciduous broad-leaved mixed forest growing in yellow lime soil.

\section{Plant materials}

We sampled 13 common canopy and sub-canopy woody angiosperm species in 12 plant families in August (Table 1). We sampled saplings or young trees 2-4 m tall that occurred either in canopy gaps created by natural disturbance or near clearings associated with forest roads to ensure that all samples experienced similar light environments. All 13 species were dominant tree species at the two sites.

\section{In situ photosynthetic gas exchange and chlorophyll $a$ fluorescence measurements}

A branch (0.4-0.7 $\mathrm{m}$ long) from each tree was detached from the top or middle of the sunny (south-facing) side of the canopy using pruning shears mounted on a $5 \mathrm{~m}$ pole. The detached branch was immediately immersed in a water-filled bucket. Then, the end of each branch was re-cut twice under water, ensuring continuum of the xylem conduit.

Theoretically, $g_{\mathrm{s}}$ is coupled to leaf specific hydraulic conductivity $\left(K_{\text {lnoon }}\right)$ and $\Psi_{\min }$ at noon as follows (Oren et al. 1999):

$$
g_{\mathrm{s}}=\frac{K_{\operatorname{lnoon}} \times\left(\Psi_{\min }-\Psi_{\mathrm{s}}\right)}{D}
$$

Where $D$ is vapour pressure deficit and $\Psi_{\mathrm{s}}$ is soil water potential.

To obtain $g_{\mathrm{s}}$ under similar conditions of $D$, we measured $g_{\mathrm{s}}$ of new, fully expanded leaves on detached branches using a LI-6400 photosynthesis system (LI-COR, Lincoln, NE, USA) in a blue-red light source leaf chamber with $1000 \mu \mathrm{mol} \cdot \mathrm{m}^{-2} \cdot \mathrm{s}^{-1}$ light intensity, $25^{\circ}$ $\mathrm{C}-30^{\circ} \mathrm{C}$ leaf temperature (ambient temperature ranged from $25^{\circ} \mathrm{C}-32{ }^{\circ} \mathrm{C}$ ), an airflow rate of $400 \mu \mathrm{mol} \cdot \mathrm{s}^{-1}$, and $50 \%-70 \%$ relative humidity (ambient, $40 \%-80 \%$ ) to maintain $D$ between 0.8 and $1.2 \mathrm{kPa}$. Instantaneous photosynthetic rate $\left(P_{\mathrm{n}}\right)$ under similar conditions of $D$ was also recorded at the same time. Measurements were conducted at midday, around 11:30-14:00 Beijing Standard Time.

Chlorophyll $a$ fluorescence, $F_{\mathrm{o}}$, and $F_{\mathrm{m}}$ (minimum and maximum fluorescence yields corresponding to open and closed reaction centre traps, respectively) were measured in the same leaves used to measure $g_{\mathrm{s}}$ with a handy-PEA portable fluorometer (Hansatch Instruments, Norfolk, UK) operated at $100 \%$ maximum excitation light intensity. Before measurements, the leaves were darkened for at least $30 \mathrm{~min}$. The maximum quantum efficiency of PSII photochemistry, $F_{\mathrm{v}} / F_{\mathrm{m}}\left(=\left(F_{\mathrm{m}}-F_{\mathrm{o}}\right) / F_{\mathrm{m}}\right)$, can provide a simple and rapid way of monitoring stress (Baker 2008). Non-stressed plants have an $F_{\mathrm{v}} / F_{\mathrm{m}}$ ratio of 0.75-0.85 (Araus and Hogan 1994; Ogaya et al. 2011).

\section{Leaf water potential}

The midday leaf water potential $\left(\Psi_{\min }\right)$ was determined for each species at the two sites using a PSYPRO Water Potential System (Wescor, Logan, UT, USA). The measurements were carried out between 11:30 and 14:00 h Beijing Standard Time on leaves from the detached branches.

\section{Hydraulic conductance and vulnerability to xylem cavitation}

In early morning, branches near those used to measure $g_{\mathrm{s}}$ were collected to measure $K_{\mathrm{l}}$ and the vulnerability curve. Briefly, four to nine sun-exposed shoots (2-4

Table 1 Characteristics of the 13 tree species from the karst area of southwestern China included in this study

\begin{tabular}{|c|c|c|c|c|}
\hline Species & Family & Leaf phenology & Location & Site \\
\hline Alangium chinense (Lour.) Harms subsp. chinense & Alangiaceae & $\mathrm{D}$ & $\mathrm{HJ}$ & $\mathrm{HJ}$ \\
\hline Carpinus pubescens Burkill & Betulaceae & $\mathrm{D}$ & PD & PD \\
\hline Daphniphyllum oldhami (Hemsl.) Rosenth. & Daphniphyllaceae & $\mathrm{E}$ & PD & PD \\
\hline Ficusbenguetensis Merrill & Moraceae & E & HJ & HJ \\
\hline Itea chinensis Hook. \& Arn. & Saxifragaceae & $\mathrm{E}$ & PD & PD \\
\hline Ligustrum lucidum W. T. Aiton & Oleaceae & $\mathrm{E}$ & PD & PD \\
\hline Lindera communis Hemsl. & Lauraceae & E & PD & PD \\
\hline Lithocarpus glaber (Thunb.) Nakai & Fagaceae & $\mathrm{E}$ & PD & PD \\
\hline Mallotus japonicus (L. f.) Müll. var. floccosus & Euphorbiaceae & $\mathrm{D}$ & HJ & HJ \\
\hline Picrasma quassioides (D. Don) Bennett & Simaroubaceae & $\mathrm{D}$ & $\mathrm{HJ}$ & $\mathrm{HJ}$ \\
\hline Platycarya longipes Wu & Juglandaceae & $\mathrm{D}$ & PD & PD \\
\hline Sapium sebiferum (L.) Roxb. & Euphorbiaceae & $\mathrm{D}$ & HJ & HJ \\
\hline Stachyurus obovatus (Rehder) Handel-Mazzetti & Stachyuraceae & $E$ & PD & PD \\
\hline
\end{tabular}

$D$ Winter deciduous, $E$ Evergreen, $H J$ Huajiang site, $P D$ Puding site 
years old) of $0.4-0.7 \mathrm{~m}$ were cut, immediately wrapped in moist paper towels, and carried to the laboratory, where they were re-cut to $17-19 \mathrm{~cm}$ lengths under water for hydraulic measurement. In an air-conditioned laboratory $\left(26^{\circ} \mathrm{C}\right)$, maximum flow rate was measured with a precision balance (Sartorius, BP221S, Göttingen, Germany) under $8 \mathrm{kPa}$ hydrostatic pressure after air emboli were clear by perfusion with $110 \mathrm{kPa}$ distilled water (filtered to $0.2 \mu \mathrm{m}$ ) for $30 \mathrm{~min}$. Measurements were not initiated until after $\sim 2 \mathrm{~min}$, when the flow rates stabilized. The efflux changes were measured every $30 \mathrm{~s}$ to obtain the flow rate. The $K_{1}\left(\mathrm{~kg} \cdot \mathrm{m}^{-1} \cdot \mathrm{MPa}^{-1} \cdot \mathrm{s}^{-1}\right)$ was calculated by dividing maximum flow rate by the leaf area distal to the measured sample and by pressure gradient. Leaf area was measured and calculated with a scanner and WinFOLIA software (Regent Instruments, Quebec City, Canada).

Vulnerability of the xylem to cavitation was characterized using a vulnerability curve as described by Sperry and Saliendra (1994). Stems were inserted into a collar and sealed with both ends protruding. Air was injected into the collar to a desired pressure, which was maintained for $15 \mathrm{~min}$ and then slowly decreased to $0.1 \mathrm{MPa}$. Afterwards, hydraulic conductivity was re-measured. This procedure was repeated until more than $90 \%$ loss in conductivity was reached. The percentage loss of conductivity $(P L C)$ following each pressurization of the chamber was calculated as $P L C=100 \times\left(K_{\mathrm{h}}-K_{\mathrm{hi}}\right) / K_{\mathrm{h}}$, where $K_{\mathrm{hi}}$ is the hydraulic conductivity of the sample measured after each chamber pressurization. Vulnerability curves were fitted with an exponential sigmoidal equation (Pammenter and Vander Willigen 1998):

$$
P L C=\frac{100}{1+e^{a(\Psi-b)}}
$$

where $\Psi$ is the negative of the injection pressure and $a$ and $b$ are coefficients estimated by non-linear regression in SPSS 10.0 (IBM, Chicago, IL, USA). The coefficient $b$ represents $\Psi_{50}$.

The $15-17 \mathrm{~cm}$ long stem as applied in the present study, may cause an open-vessel artefact. To check this possibility, firstly we traced the book Woods in China (Cheng et al. 1992), in which the data of the sampled species showed that the maximum vessel element's length ranged from 150 (Picrasma quassioides) to $2000 \mu \mathrm{m}$ (Daphniphyllum oldhami). Secondly, to measure the VC curve, we applied a $0.1 \mathrm{MPa}$ in the collar to re-measure hydraulic conductivity to minimize the possible open-vessel artefact (Cochard et al. 1992). Further, some studies showed that generally the current-year branches of woody species (diffuse-porous and ring-porous) have the maximum vessel length less than $16 \mathrm{~cm}$ in different forest ecosystems (eg. Cochard et al.
1990; Sperry et al. 1994; Hacke et al. 2006; Jacobsen et al. 2008). However, we also noticed some woody species (eg. Quercus rubra) have vessels with length of more than $1 \mathrm{~m}$ in the literature (Ennajeh et al. 2011), which means there is a little chance that some branch samples in the present study may have open-vessels at both ends.

We calculated the daily maximum percentage loss of leaf hydraulic conductivity (Loss), as well as $K_{1}$ at noon $\left(K_{\text {lnoon }}\right)$, by using field water potential measurements and the vulnerability curve (Johnson et al. 2009). It has been reported that xylem embolism is likely a critical element for the decrease of leaf hydraulic conductance during the daytime (Kikuta et al. 1997; Woodruff et al. 2007; Johnson et al. 2010).

\section{Data analysis}

We tested the differences between evergreen and deciduous species using ANOVA and Multivariate ANOVA (MANOVA), the latter using either the identity or contrast response design (both with indistinguishable results) and using the Pillais Trace statistic test. When necessary, data were log-transformed to meet normality assumptions. Pearson correlation analysis was conducted among investigated traits. All analyses were performed using SPSS 10.0.For investigation on the relationship between $\Psi_{\min }$ and $\Psi_{50}$, data from this study as well as previously-published literature cross different ecosystems (Pockman and Sperry 2000; Choat et al. 2005; Hao et al. 2008; Markesteijn et al. 2011b) were compiled.

\section{Results}

Values of $\Psi_{\min }$ ranged from $-0.96 \mathrm{MPa}$ in Stachyurus obovatus (an evergreen species at the PD site) to -1.61 MPa in Mallotus japonicus (deciduous; HJ site), a difference of only $0.65 \mathrm{MPa}$ (Table 2). These values corresponded closely to data collected by Liu et al. 2012) at the same sites. On the contrary, there were wide variations in vulnerability curves and $\Psi_{50}$ across the 13 species (Table 2, Fig. 1). In this study, S. obovatus was the species most resistant to xylem cavitation; its $\Psi_{50}$ of 4.31 $\mathrm{MPa}$ was seven-fold more negative than the least resistant species, Daphniphyllum oldhami (evergreen; PD). The Loss at noon, calculated using field water potential measurements and the vulnerability curve, varied substantially in the field, from $1.39 \%$ in Itea chinensis (evergreen; PD) to $90.07 \%$ in Sapium sebiferum (deciduous; HJ) (Table 2). As an extension of the study by Johnson et al. (2009), we compiled from the literature a large dataset on embolism of native woody species across various ecosystems (Pockman and Sperry 2000; Bucci et al. 2003; Nardini et al. 2003; Brodribb and Holbrook 2004; Meinzer et al. 2004; Choat et al. 2005; Brodribb and Holbrook 2006; Bhaskar et al. 2007; Hao et al. 2008; Johnson et al. 2009; Markesteijn et al. 2011b; Guyot et 
Table 2 Summary parameters for the 13 woody karst species from southwestern China examined in this study. Minimum leaf water potential $\left(\psi_{\mathrm{min}}, \mathrm{MPa}\right)$, photosynthetic rate $\left(P_{\mathrm{n}}, \mu \mathrm{mol} \cdot \mathrm{m}^{-2} \cdot \mathrm{s}^{-1}\right)$, stomatal conductance $\left(g_{\mathrm{s}}, \mathrm{mol} \cdot \mathrm{m}^{-2} \cdot \mathrm{s}^{-1}\right)$, leaf specific conductivity $\left(K_{\mathrm{l}}\right.$, $\left.\mathrm{kg} \cdot \mathrm{m}^{-1} \cdot \mathrm{MPa}^{-1} \cdot \mathrm{s}^{-1}\right)$, xylem tension at $50 \%$ cavitation $\left(\psi_{50}, \mathrm{MPa}\right)$, leaf specific conductivity at noon $\left(K_{\text {Inoon, }} \mathrm{kg} \cdot \mathrm{m}^{-1} \cdot \mathrm{MPa}^{-1} \cdot \mathrm{s}^{-1}\right), \mathrm{loss}$ percentage of $K_{l}$ at noon (Loss, \%), maximum quantum efficiency of photosystem $\|\left(F_{\mathrm{v}} / F_{\mathrm{m}}\right)$, and hydraulic safety margin (Margin, Mpa) were assessed for each species. Standard errors were shown in parentheses

\begin{tabular}{|c|c|c|c|c|c|c|c|c|c|}
\hline Species & $\psi_{\min }$ & $P_{\mathrm{n}}$ & $g_{\mathrm{s}}$ & $K_{1}$ & $\psi_{50}$ & $K_{\text {Inoon }}{ }^{a}$ & $\operatorname{Loss}^{a}$ & $F_{\mathrm{v}} / F_{\mathrm{m}}$ & Margin $^{b}$ \\
\hline Alangium chinense ssp. chinense & $-1.50(0.25)$ & $10.55(1.24)$ & $0.38(0.10)$ & $6.06(1.13)$ & $-1.08(0.23)$ & 1.94 & 67.95 & $0.75(0.01)$ & -0.42 \\
\hline Carpinus pubescens & $-0.99(0.32)$ & $6.90(2.96)$ & $0.23(0.08)$ & $2.68(0.88)$ & $-1.39(0.15)$ & 1.77 & 33.82 & $0.78(0.02)$ & 0.4 \\
\hline Daphniphyllum oldhami & $-1.12(0.21)$ & $4.05(0.71)$ & $0.11(0.03)$ & $0.91(0.32)$ & $-0.62(0.08)$ & 0.09 & 89.84 & $0.79(0.01)$ & -0.5 \\
\hline Ficus benguetensis & $-1.15(0.62)$ & $5.12(0.23)$ & $0.13(0.05)$ & $2.17(1.27)$ & $-0.66(0.09)$ & 0.42 & 80.68 & $0.80(0.01)$ & -0.49 \\
\hline Itea chinensis & $-0.99(0.18)$ & $7.46(1.65)$ & $0.14(0.02)$ & $1.40(0.49)$ & $-2.54(0.26)$ & 1.38 & 1.39 & $0.76(0.02)$ & 1.55 \\
\hline Lindera communis & $-0.98(0.06)$ & $9.86(0.53)$ & $0.21(0.01)$ & $0.51(0.21)$ & $-0.85(0.12)$ & 0.20 & 60.13 & $0.79(0.02)$ & -0.13 \\
\hline Lithocarpus glaber & $-1.08(0.18)$ & $9.71(3.79)$ & $0.17(0.12)$ & $1.70(0.53)$ & $-1.57(0.32)$ & 1.16 & 31.69 & $0.81(0.01)$ & 0.49 \\
\hline Ligustrum lucidum & $-1.09(0.16)$ & $11.49(1.23)$ & $0.32(0.15)$ & $1.44(0.19)$ & $-3.67(0.60)$ & 1.13 & 21.37 & $0.80(0.01)$ & 2.58 \\
\hline Mallotus japonicus var. floccosus & $-1.61(0.23)$ & $7.03(0.66)$ & $0.34(0.12)$ & $3.53(0.63)$ & $-1.12(0.12)$ & 0.95 & 73.19 & $0.77(0.03)$ & -0.49 \\
\hline Platycarya longipes & $-1.07(0.19)$ & $10.71(0.82)$ & $0.31(0.05)$ & $2.46(0.55)$ & $-1.50(0.04)$ & 1.59 & 35.56 & $0.76(0.01)$ & 0.43 \\
\hline Picrasma quassioides & $-1.38(0.05)$ & $10.49(0.66)$ & $0.30(0.08)$ & $5.60(0.49)$ & $-0.93(0.13)$ & 0.20 & 87.84 & $0.77(0.01)$ & -0.77 \\
\hline Stachyurus obovatus & $-0.96(0.56)$ & $5.42(2.09)$ & $0.14(0.03)$ & $0.86(0.19)$ & $-4.31(0.39)$ & 0.74 & 14.07 & $0.80(0.02)$ & 3.35 \\
\hline Sapium sebiferum & $-1.42(0.31)$ & $10.37(1.71)$ & $0.23(0.02)$ & $4.52(0.82)$ & $-0.65(0.08)$ & 0.45 & 90.07 & $0.84(0.02)$ & -0.77 \\
\hline
\end{tabular}

${ }^{a}$, calculated using laboratory-generated vulnerability curve and field water potential measurements. ${ }^{\mathrm{b}}$, calculated as the difference between $\psi_{50}$ and minimum water potential

al. 2012). Loss values for a total 75 species were bimodally-distributed (Fig. 2, Additional file 1: Table S1). The $K_{\mathrm{l}}$ and $K_{\mathrm{l}}$ at noon $\left(K_{\mathrm{lnoon}}\right)$ each varied by more than 10 -fold. On average, the evergreen species displayed significantly higher $\Psi_{\min }$ and lower $K_{1}$ than the deciduous species, but the differences in $K_{\text {lnoon }}$ between groups was not significant (Table 3). Evergreen species also tended to exhibit lower loss $(42.7 \%)$ of $K_{\text {lnoon }}$ and lower $\Psi_{50}$ than deciduous ones (Table 3 ).

The $F_{\mathrm{v}} / F_{\mathrm{m}}$ ratios of all 13 species were above 0.75 (Table 2), suggesting that no physiological stress was experienced at noon. When the species were classified into two groups based on daily maintenance of hydraulic conductivity $(10 \%-40 \%$ and $60 \%-90 \%$; Johnson et al. 2009), no significant differences in $F_{\mathrm{v}} / F_{\mathrm{m}}$ ratio was detected between the groups (Fig. 3). There were substantial variations among species in $g_{\mathrm{s}}$ at noon measured under constant vapour pressure deficit (Table 2). The $P_{\mathrm{n}}$ varied among species by a factor of about three, whereas variation in $g_{\mathrm{s}}$ was each several times greater. On average, evergreen species had significantly lower $g_{s}$, and higher hydraulic safety margin than deciduous ones. A MANOVA using the Pillais Trace statistic revealed that the two groups, on the whole, was not significantly different for the 8 leaf traits (Table 3).

The values of $g_{\mathrm{s}}$ were positively correlated with $K_{\mathrm{l}}$ across species $(P=0.013)$, while $K_{\text {lnoon }}$ was not significantly associated with $g_{\mathrm{s}}(P=0.073$; Fig. 4). A strong association between $\Psi_{\text {min }}$ and $\Psi_{50}$ across different ecosystems was demonstrated; species with lowest $\Psi_{\text {min }}$ were most resistant to drought-induced cavitation (Fig. 5). However, no significant relationship was detected from data pooled from this study alone (Fig. 5, Table 4$). \Psi_{50}$ was only marginally positively associated with $K_{1}$ (Table $4, P=0.08$ ), consistent with previous results either across many vegetation types (Maherali et al. 2004) or within specific ecosystems (e.g., temperate forest; Maherali et al. 2006). There was no association between Loss and $F_{\mathrm{v}} / F_{\mathrm{m}}$ (Table $\left.4, P=0.58\right)$.

\section{Discussion}

The loss of leaf conductivity in the field, most likely due to leaf or stem xylem embolism (Domec et al. 2006; Woodruff et al. 2007; Johnson et al. 2009; Blackman et al. 2017), can be accurately predicted from field measurements of leaf water potentials and laboratory-generated vulnerability curves (Brodribb and Holbrook 2004; Johnson et al. 2009). The 13 species in this study varied substantially in Loss in the field, from $1.39 \%$ in the evergreen I. chinensis to $90.07 \%$ in the deciduous S. sebiferum in the field. The large variation in Loss in the karst area in China argued against the hypothesis that plants control xylem tension above threshold for cavitation. Interestingly, Loss in the current study did not significantly depress the efficiency of PSII and/or the photosynthetic rate, suggesting that photosynthetic capacity was not affected by xylem cavitation, even in the extreme case of S. sebiferum, which lost $90 \%$ hydraulic conductivity at noon.

Loss values for a total 75 species was bimodally-distributed, further supporting the idea that 


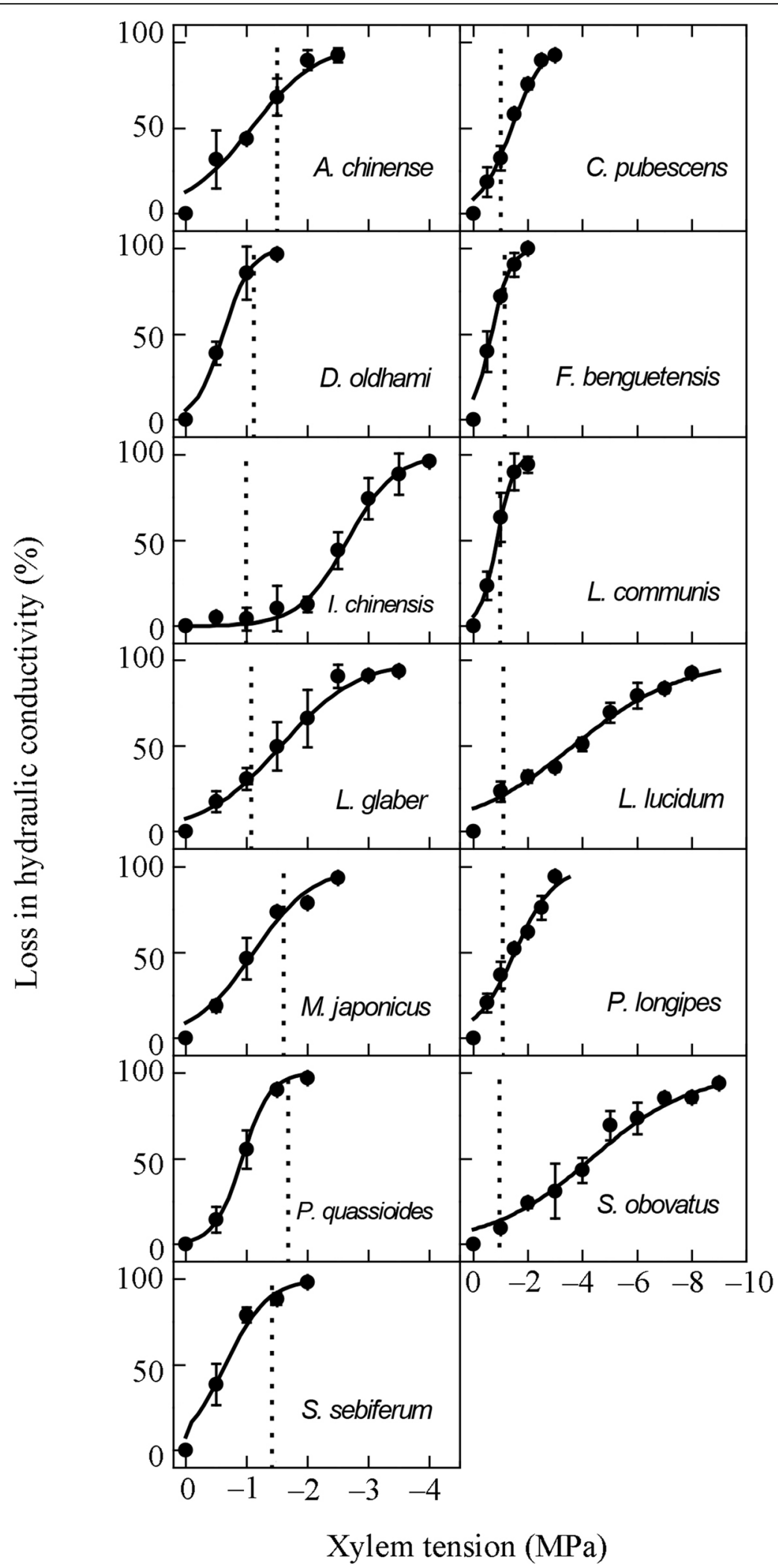

Fig. 1 Loss of hydraulic conductivity as a function of xylem pressure for 13 karst woody species from China. Dashed lines represent minimum leaf water potential and vertical error bars indicate standard error. Graphs for the 13 species are alphabetically arranged 


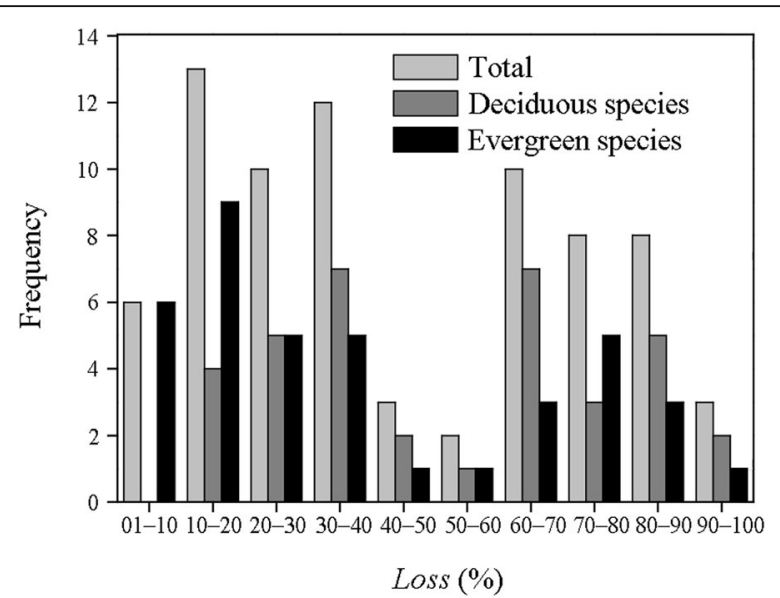

Fig. 2 Frequency distribution of per cent loss of leaf hydraulic conductivity (Loss). Data for 75 species (36 deciduous, 39 evergreen) were compiled from this and other studies (see text for references) to expand the analysis of Johnson et al. (2009). Data were binned into intervals of 10\% Loss (e.g., 0-9\%, 10\%-19\%) for deciduous, evergreen, and total species. Loss in deciduous species was more evenly distributed than in evergreen species, with 18 species having less than 50\% and 18 having more than 50\% Loss, while evergreen species ( 25 out of 39 ) tended to have less than $50 \%$ Loss

plants can adopt two strategies to deal with xylem cavitation: 1) maintain the water potential above the cavitation threshold, or 2) tolerate massive xylem cavitation and subsequent recovery (Jones and Sutherland 1991; Johnson et al. 2009). Some plants can operate well beyond the point of xylem failure via stomata closure, but they sacrifice carbon fixation, because ambient $\mathrm{CO}_{2}$ cannot diffuse into leaf intercellular spaces. Other plants can tolerate massive cavitation over the short term, allowing photosynthesis to continue. In fact, massive cavitation was experimentally demonstrated to help relieve water stress temporarily by releasing water from

Table 3 Mean values of hydraulic and leaf traits for evergreen and deciduous functional groups and the results of MANOVA to test the effect of leaf phenology on measured traits

\begin{tabular}{lll}
\hline Traits & Deciduous & Evergreen \\
$\psi_{\min }{ }^{*}$ & -1.33 & -1.05 \\
$P_{\mathrm{n}}$ & 9.34 & 7.59 \\
$g_{\mathrm{s}}^{* *}$ & 0.3 & 0.17 \\
$K_{\mathrm{l}}^{* * *}$ & 4.14 & 1.28 \\
$\psi_{50}$ & -1.11 & -2.03 \\
$K_{\text {Inoon }}$ & 1.23 & 0.73 \\
Loss & 64.7 & 42.7 \\
Margin* & -0.27 & 0.98 \\
MANOVA & $\boldsymbol{F}$ & $\boldsymbol{P}$ \\
Functional group & 2.654 & 0.181 \\
\hline
\end{tabular}

${ }^{*} P<0.05,{ }^{* *} P<0.01,{ }^{* * *} P<0.001$. Trait abbreviations and units as in Table 2. MANOVA was performed using the Pillais Trace statistic $(=0.181)$

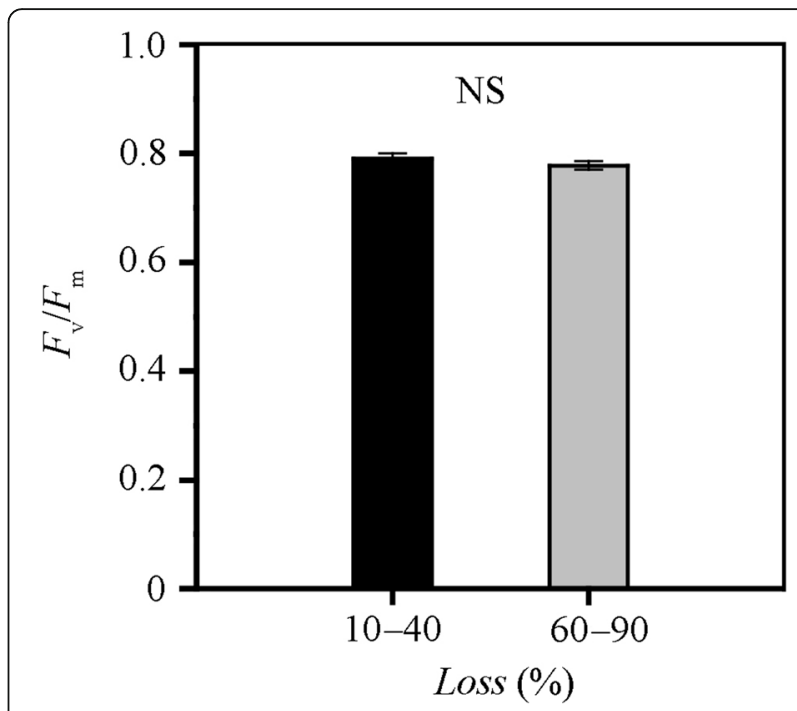

Fig. 3 Maximum quantum efficiency of photosystem II $\left(F_{\mathrm{v}} / F_{\mathrm{m}}\right)$ of karst plants at noon. Plants from the karst area of China that maintained leaf hydraulic conductivity loss below $40 \%$ of maximum (five species, black column) were compared to those that tolerated more than 60\% (six species, grey column). Two extreme cases (Itea chinensis, an evergreen species that can maintain $98.61 \%$ leaf specific hydraulic conductivity $\left(K_{1}\right)$ and Sapium sebiferum, a deciduous species that can tolerate $90.07 \%$ loss of $K_{1}$ at noon) were excluded from the analysis. There was no significant difference in $F_{v} /$ $F_{\mathrm{m}}$ between these two groups $(P=0.339)$

embolizing conduits to the transpiration stream (Logullo and Salleo 1992; Holtta et al. 2012) and to lower the risk of xylem wall implosion (Pratt et al. 2008).

There were no sign of physiological stress in the 13 species at noon and no significant differences in $F_{\mathrm{v}} / F_{\mathrm{m}}$ between plants with less than $40 \%$ and more than $60 \%$ Loss. The relationship between Loss and $F_{\mathrm{v}} / F_{\mathrm{m}}$ was also not significant. Thus, plants adopting both strategies could maintain PSII efficiency at noon in the karst region of China, possibly via different hydraulic solutions. For example, the radical strategy allowing massive xylem cavitation could temporarily relieve water stress and therefore might maintain photosynthesis for hours before leaf water reserves are exhausted (Logullo and Salleo 1992; Holtta et al. 2012). Such massive embolized conduits could be expected to be fully refilled before the following dawn. In fact, $\Psi_{\text {predawn }}$ values of two fig species in the karst region of southwestern China were close to zero (Liu et al. 2012b), suggesting they had fully refilled embolized conduits. However, another survey of 50 karst woody species at forest site demonstrated that $\Psi$ predawn values were about - 1.0 MPa (Liu et al. 2012a), suggesting that embolisms persisted. Such a large discrepancy between two studies at similar sites deserves further investigation. For the conservative strategy, these plants might develop a stronger ability to dissipate excessive absorbed light energy as nonphotochemical quenching 


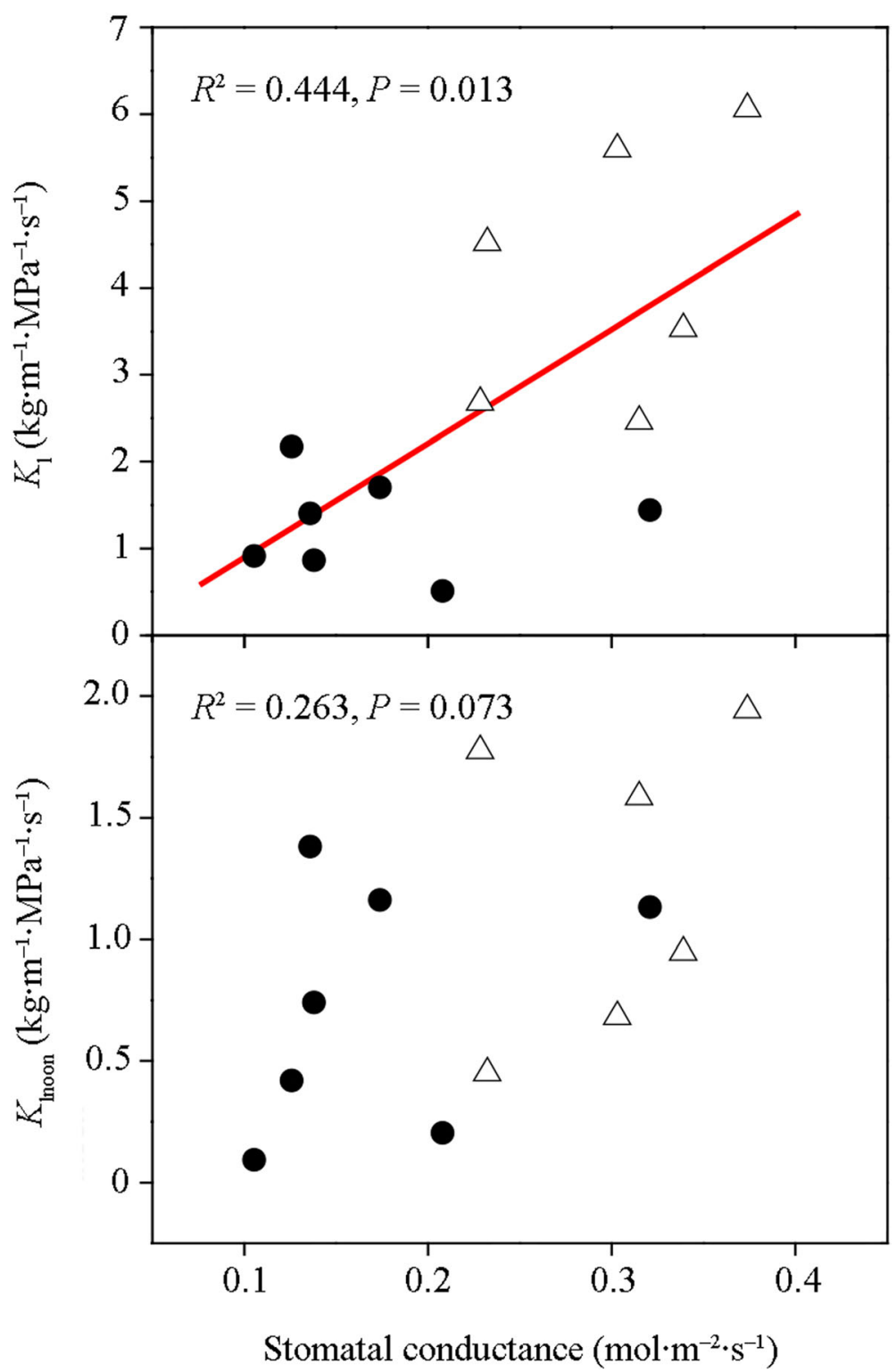

Fig. 4 Stomatal conductance as a function of leaf specific hydraulic conductivity for 13 karst woody species. Both maximum $K_{\perp}$ and $K_{1}$ at noon $\left(K_{\text {Inoon }}\right)$ were measured at a vapour pressure deficit of $1 \mathrm{kPa}$ for 13 karst woody species in southwestern China. The solid line represents best-fit linear regression. Open triangles and closed dots represent deciduous and evergreen species, respectively

(NPQ) to alleviate excitation pressure at PSII reaction centres and consequently maintain PSII maximum quantum efficiency (Baker 2008). Interestingly, it is noteworthy that $g_{\mathrm{s}}$ had no association with Loss (Table 4); possibly whole-plant hydraulic adjustment participates in the regulation of Loss, which merit further investigation.

The previously reported strong association between $\Psi_{50}$ and $\Psi_{\text {min }}$ across species in some ecosystems (e.g., Pockman and Sperry 2000; Markesteijn et al. 2011b; Choat et al. 2012) was not observed by using our data in the current study, suggesting that xylem resistance is not necessarily related to the tensions experienced in the karst area. In fact, the absence of such an association could be explained by the fact that karst plants maintained a very narrow range of $\Psi_{\min }$ (from $-0.96 \mathrm{MPa}$ in S. obovatus to $-1.61 \mathrm{MPa}$ in M. japonicus) in the present study. Such "isohydric" regulation behaviour may also have been seen in other studies in this area (Yu et al. 2002; Liu et al. 2012a). For example, Liu et al. (2012a) reported a $\Psi_{\min }$ range from about -1 to $-1.8 \mathrm{MPa}$ in the wet season and 1 to $-2.6 \mathrm{MPa}$ in the dry season (50 tree species), and $\mathrm{Yu}$ et al. (2002) reported a $\Psi_{\text {min }}$ range from -0.79 to $-2.2 \mathrm{MPa}$ in the wet season (25 tree species). In other words, plants with isohydric regulation might 


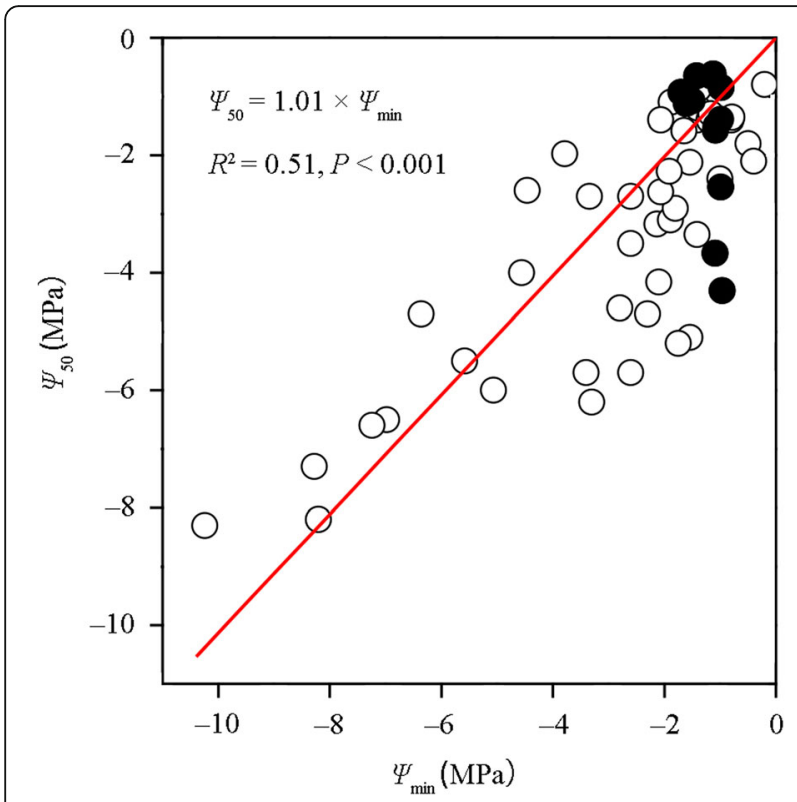

Fig. 5 Correlation between minimum leaf water potential $\left(\Psi_{\text {min }}\right)$ and vulnerability to cavitation $\left(\psi_{50}\right)$. Data for 56 plant species were compiled from this and other studies (see text for references). The regression coefficient and its level of significance are given. The closed dots represent data from the 13 karst species from this study. There was no significant association between $\psi_{\min }$ and $\psi_{50}(P=$ 0.121) when only these data were analysed

have larger variations in loss of hydraulic conductivity than "anisohydric" one. For example, a relatively isohydric piñon pine experienced loss of root hydraulic conductivity ranging from 0 to $100 \%$ PLC during a seven-year observation period, compared with the constant and very small $P L C$ of a co-occurring anisohydric juniper (McDowell 2011).

Theoretical assessments of the role of stomatal regulation on hydraulic conductance revealed a positive, linear relationship between $g_{\mathrm{s}}$ and $K_{\mathrm{l}}$ if the whole-plant water pressure gradient and $D$ between the leaf and air remain similar (Sperry et al. 1993; Oren et al. 1999). Given that the species studied here had similar $\Psi_{\text {min }}$ and $D$, the close relationship between $K_{\mathrm{l}}$ and $g_{\mathrm{s}}$ found was consistent with previous studies in other ecosystems (Hubbard et al. 2001; Santiago et al. 2004). Interestingly, the $K_{\text {lnoon }}$ was not significantly correlated with $g_{\mathrm{s}}$; similarly, Santiago et al. (2004) reported that the correlation coefficient between $K_{\text {init }}$ and $g_{\mathrm{s}}$ was lower than that between $K_{\operatorname{lmax}}$ and $g_{\mathrm{s}}$. The absence of correlation between $K_{\text {Inoon }}$ and $g_{\mathrm{s}}$ could have many explanations. For example, leaf capacity may decouple the relationship between $K_{\text {lnoon }}$ and $g_{s}$.

Evergreen species, with $42.7 \%$ Loss at midday, tended to maintain xylem conductivity better than deciduous species (with 64.7\%) in the current study, although the difference between groups was not significant $(P=$ 0.221 ). This tendency was also seen in the more even distribution of Loss frequencies in deciduous than in evergreen species; 18 deciduous species had less than 50\% and 18 had more than 50\% Loss, while more evergreen species ( 25 of 39 ) had less than $50 \%$ Loss. These results were consistent with our expectation that evergreens could avoid massive cavitation at midday better than co-occurring deciduous species.

A MANOVA revealed a non-significant contrast between deciduous and evergreen species in hydraulic and associated leaf traits, which means these two life-history adaptations are likely part of a continuum of strategies (Borchert 1994; Brodribb et al. 2002; Williams et al. 2008; Ishida et al. 2010). On the other hand, deciduous species were geared towards higher hydraulic conductance, photosynthetic rate, stomatal conductance, lower hydraulic safety margin and lower cavitation-resistance and minimum water potential than co-occurring evergreen species, in agreement with previous reports (Gartner et al. 1990; Sobrado 1993; Choat et al. 2005; Chen et al. 2009; Markesteijn et al. 2011b; Fu et al. 2012; O'Brien et al. 2017). The strategy of higher tolerance of

Table 4 Magnitude and statistical significance of Pearson correlations between hydraulic and leaf traits of 13 karst woody species in southwestern China

\begin{tabular}{|c|c|c|c|c|c|c|c|c|c|}
\hline Trait & $\psi_{\min }$ & $P_{\mathrm{n}}$ & $g_{\mathrm{s}}$ & $K_{1}$ & $\psi_{50}$ & $K_{\text {Inoon }}$ & LOSS & $F_{\mathrm{v}} / F_{\mathrm{m}}$ & Margin \\
\hline$\overline{\psi_{\min }}$ & 1 & & & & & & & & \\
\hline$P_{\mathrm{n}}$ & -0.229 & 1 & & & & & & & \\
\hline$g_{\mathrm{s}}$ & $-0.621^{*}$ & $0.704^{* *}$ & 1 & & & & & & \\
\hline$K_{1}$ & $-0.815^{*}$ & 0.422 & $0.666^{*}$ & 1 & & & & & \\
\hline$\psi_{50}$ & -0.452 & 0.000 & 0.075 & 0.414 & 1 & & & & \\
\hline$K I_{\text {noon }}$ & -0.040 & 0.350 & 0.513 & 0.333 & -0.237 & 1 & & & \\
\hline Loss & $-0.654^{*}$ & -0.067 & 0.136 & 0.505 & $0.804^{* *}$ & -0.519 & 1 & & \\
\hline$F_{\mathrm{v}} / F_{\mathrm{m}}$ & 0.125 & -0.046 & -0.412 & -0.247 & -0.032 & $-0.568^{*}$ & 0.168 & 1 & \\
\hline Margin & $0.591^{*}$ & -0.055 & -0.187 & -0.541 & $-0.984^{* *}$ & 0.216 & $-0.853^{* *}$ & 0.063 & 1 \\
\hline
\end{tabular}

${ }^{*} P<0.05,{ }^{* *} P<0.01,{ }^{* * *} P<0.001$. Trait abbreviations and units as in Table 2 
hydraulic loss seen in deciduous species might guarantee sufficient carbon gain when water is abundant, or water stress could be relieved temporarily by releasing water from embolizing conduits to the transpiration stream, which might favour fast growth closely associated with a higher photosynthetic rate during the growing season (Santiago et al. 2004; Chen et al. 2009). During droughts or winter, deciduous species minimize transpiration by shedding their leaves, thereby greatly reducing the risk of long-term hydraulic failure (Maherali et al. 2004).

In conclusion, we found no evidence that karst woody species in southwestern China could control xylem tension to avoid substantial xylem cavitation. The variation in loss of leaf conductivity in this study did not significantly depress the efficiency of PSII. $\Psi_{50}$ was not related to $\Psi_{\text {min }}$. The frequency distribution of the loss of leaf hydraulic conductivity due to xylem cavitation at noon in a total of 75 species from this study and the literature supported the idea presented by Johnson et al. (2009) that there may exist two different strategies for the daily maintenance of hydraulic conductivity. The co-occurring evergreen and deciduous woody species of karst in southwestern China differed significantly in some stem hydraulic and associated leaf traits. Under the high variable daily moisture conditions in karst areas in China, the interactions between isohydric regulation behaviour, low cavitation resistance (Fan et al. 2011), and other hydraulic traits (particularly root systems) for maintaining homeostatic water balance in whole plants are worthy of further study. A more sophisticated design of field investigation on a single species in different seasons, to explore the relationship between $P L C, F_{\mathrm{v}} / F_{\mathrm{m}}$, water storage capacity and NPQ, is necessary for future study.

\section{Additional file}

Additional file 1: Table S1. Species measured, growth form, midday leaf water potential $\left(\psi_{\mathrm{min}}\right)$, the percentage loss of conductivity $(P L C)$, the $\psi$ at which a $50 \%$ loss in conductivity occurs $\left(\psi_{50}\right)$, the method used to determine PLC, the ecosystem where the measurement was conducted, and the reference. (DOCX $38 \mathrm{~kb}$ )

\section{Abbreviations}

HJ: Huajiang site; $K_{\text {init: }}$ initial leaf hydraulic conductance; MAP: mean annual precipitation; PD: Puding site; PLC: percentage loss of conductivity;

PSII: photosystem II; $\psi_{\text {predawn: }}$ Predawn leaf water potential

\section{Acknowledgements}

Not applicable.

\section{Funding}

This study was financially supported by the National Key Research and Development Program of China (2016YFA0600802) and State Key Project of Research and Development Plan (2016YFC0502104).

\section{Authors' contributions}

DF and SZ contributed equally to this paper. HY, QW and XX carried out the experiment, DF, XW and SZ performed the statistical analyses and drafted the manuscript. All authors read and approved the final manuscript.

Ethics approval and consent to participate

Not applicable.

\section{Competing interests}

The authors declare that they have no competing interests.

\section{Author details}

${ }^{1}$ College of Forestry, Beijing Forestry University, Beijing 100083, China. ${ }^{2}$ State Key Laboratory of Vegetation and Environmental Change, Institute of Botany, Chinese Academy of Sciences, Beijing 100093, China. ${ }^{3}$ Inner Mongolia Forestry Monitoring and Planning Academy, Hohhot 010020, China. ${ }^{4}$ China Meteorological Administration, Beijing 100081, China.

Received: 15 June 2018 Accepted: 14 December 2018

Published online: 30 December 2018

\section{References}

Araus JL, Hogan KP (1994) Leaf structure and patterns of photoinhibition in two neotropical palms in clearings and forest understory during the dry season. Am J Bot 81:726-738

Baker NR (2008) Chlorophyll fluorescence: a probe of photosynthesis in vivo. Annu Rev Plant Biol 59:89-113

Bhaskar R, Valiente-Banuet A, Ackerly DD (2007) Evolution of hydraulic traits in closely related species pairs from Mediterranean and nonmediterranean environments of North America. NewPhyt 176:718-726

Blackman CJ, Aspinwall MJ, Tissue DT, Rymer PD (2017) Genetic adaptation and phenotypic plasticity contribute to greater leaf hydraulic tolerance in response to drought in warmer climates. Tree Physiol 37:583-592

Borchert R (1994) Soil and stem water storage determine phenology and distribution of tropical dry forest trees. Ecology 75:1437-1449

Brodribb TJ, Holbrook NM (2004) Diurnal depression of leaf hydraulic conductance in a tropical tree species. Plant Cell Environ 27:820-827

Brodribb TJ, Holbrook NM (2006) Declining hydraulic efficiency as transpiring leaves desiccate: two types of response. Plant Cell Environ 29:2205-2215

Brodribb TJ, Holbrook NM, Gutierrez MV (2002) Hydraulic and photosynthetic coordination in seasonally dry tropical forest trees. Plant Cell Environ 25:1435-1444

Bucci SJ, Scholz FG, Goldstein G, Meinzer FC, Sternberg LDL (2003) Dynamic changes in hydraulic conductivity in petioles of two savanna tree species: factors and mechanisms contributing to the refilling of embolized vessels. Plant Cell Environ 26:1633-1645

Chen JW, Zhang Q, Cao KF (2009) Inter-species variation of photosynthetic and xylem hydraulic traits in the deciduous and evergreen Euphorbiaceae tree species from a seasonally tropical forest in South-Western China. Ecol Res 24:65-73

Cheng JQ, Yang JJ, Liu P (1992) Woods in China. Chinese Forestry Publishing House, Beijing

Choat B, Ball MC, Luly JG, Holtum JAM (2005) Hydraulic architecture of deciduous and evergreen dry rainforest tree species from North-Eastern Australia. TreesStruct Funct 19:305-311

Choat B, Jansen S, Brodribb TJ, Cochard H, Delzon S, Bhaskar R, Bucci SJ, Feildet TS, Gleasonal SM, Hacke UG, Jacobsen AL, Lens F, Maherali H, Martínez-Vilalta J, Mayr S, Mencuccini M, Mitchell PJ, Nardini A, Pittermann J, Pratt RB, Sperry JS, Westoby M, Wright IJ, Zanne AE (2012) Global convergence in the vulnerability of forests to drought. Nature 491:752-755

Cochard H, Cruiziat P, Tyree MT (1992) Use of positive pressures to establish vulnerability curves: further support for the air-seeding hypothesis and implications for pressure-volume analysis. Plant Physiol 100:205-209

Cochard H, Melvin T, Tyree MT (1990) Xylem dysfunction in Quercus: vessel sizes, tyloses, cavitation and seasonal changes in embolism. Tree Physiol 6:393-407

Daniela D, Marc W, Heinrich S (2016) Variability of European beech wood density as influenced by interactions between tree-ring growth and aspect. Forest Ecosyst 3(1):6. https://doi.org/10.1186/s40663-016-0065-8

Domec JC, Scholz FG, Bucci SJ, Meinzer FC, Goldstein G, Villalobos-Vega R (2006) Diurnal and seasonal variation in root xylem embolism in neotropical savanna woody species: impact on stomatal control of plant water status. Plant Cell Environ 29:26-35 
Ennajeh M, Simões F, Khemira H, Cochard H (2011) How reliable is the doubleended pressure sleeve technique for assessing xylem vulnerability to cavitation in woody angiosperms? Physiol Plantar 142:205-210

Fan DY, Jie SL, Liu CC, Zhang XY, Xu XW, Zhang SR, Xie ZQ (2011) The trade-off between safety and efficiency in hydraulic architecture in 31 woody species in a karst area. Tree Physiol 31:865-877

Fu PL, Jiang YJ, Wang AY, Brodribb TJ, Zhang JL, Zhu SD, Cao KF (2012) Stem hydraulic traits and leaf water-stress tolerance are co-ordinated with the leaf phenology of angiosperm trees in an Asian tropical dry karst forest. Ann Bot 110:189-199

Gadow K, Zhang GQ, Durrheim G, Drew D, Seydack A (2016) Diversity and production in an Afromontane Forest. Forest Ecosyst. 3(1):15. https://doi.org/ 10.1186/s40663-016-0074-7

Gartner BL, Bullock SH, Mooney HA, Brown VB, Whitbeck JL (1990) Water transport-properties of vine and tree stems in a tropical deciduous forest. Am J Bot 77:742-749

Guyot G, Scoffoni C, Sack L (2012) Combined impacts of irradiance and dehydration on leaf hydraulic conductance: insights into vulnerability and stomatal control. Plant Cell Environ 35:857-871

Hacke UG, Sperry JS, Wheeler JK, Castro L (2006) Scaling of angiosperm xylem structure with safety and efficiency. Tree Physiol 26:689-701

Hao GY, Hoffmann WA, Scholz FG, Bucci SJ, Meinzer FC, Franco AC, Cao KF, Goldstein G (2008) Stem and leaf hydraulics of congeneric tree species from adjacent tropical savanna and forest ecosystems. Oecologia 155:405-415

Holtta T, Juurola E, Lindfors L, Porcar-Castell A (2012) Cavitation induced by a surfactant leads to a transient release of water stress and subsequent 'run away' embolism in scots pine (Pinus sylvestris) seedlings. J Exp Bot 63:1057-1067

Hubbard RM, Ryan MG, Stiller V, Sperry JS (2001) Stomatal conductance and photosynthesis vary linearly with plant hydraulic conductance in ponderosa pine. Plant Cell Environ 24:113-121

Ishida A, Harayama H, Yazaki K, Ladpala P, Sasrisang A, Kaewpakasit K, Panuthai S, Staporn D, Maeda T, Gamo M, Diloksumpun S, Puangchit L, Ishizuka M (2010) Seasonal variations of gas exchange and water relations in deciduous and evergreen trees in monsoonal dry forests of Thailand. Tree Physiol 30:935-945

Jacobsen AL, Pratt RB, Davis SD, Ewers FW (2008) Comparative community physiology: nonconvergence in water relations among three semi-arid shrub communities. New Phytol 180:100-113

Johnson DM, Meinzer FC, Woodruff DR, Mcculloh KA (2010) Leaf xylem embolism, detected acoustically and by cryo-SEM, corresponds to decreases in leaf hydraulic conductance in four evergreen species. Plant Cell Environ 32:828-836

Johnson DM, Woodruff DR, McCulloh KA, Meinzer FC (2009) Leaf hydraulic conductance, measured in situ, declines and recovers daily: leaf hydraulics, water potential and stomatal conductance in four temperate and three tropical tree species. Tree Physiol 29:879-887

Jones HG, Sutherland RA (1991) Stomatal control of xylem embolism. Plant Cell Environ 14:607-612

Kikuta SB, Lo Gullo MA, Nardini A, Richter H, Salleo S (1997) Ultrasound acoustic emissions from dehydrating leaves of deciduous and evergreen trees. Plant Cell Environ 20:1381-1390

Liu CC, Liu YG, Fan DY, Guo K (2012) Plant drought tolerance assessment for revegetation in heterogeneous karst landscapes of southwestern China. Flora 207:30-38

Liu JY, Fu PL, Wang YJ, Cao KF (2012b) Drought-tolerance of evergreen and deciduous figs in tropical karst forest. Plant Sci J 30:484-493

Logullo MA, Salleo S (1992) Water storage in the wood and xylem cavitation in 1-year-old twigs of Populus deltoids Bartr. Plant Cell Environ 15:431-438

Maherali H, Moura CF, Caldeira MC, Willson CJ, Jackson RB (2006) Functional coordination between leaf gas exchange and vulnerability to xylem cavitation in temperate forest trees. Plant Cell Environ 29:571-583

Maherali H, Pockman WT, Jackson RB (2004) Adaptive variation in the vulnerability of woody plants to xylem cavitation. Ecology 85:2184-2199

Markesteijn L, Poorter L, Bongers F, Paz H, Sack L (2011a) Hydraulics and life history of tropical dry forest tree species: coordination of species' drought and shade tolerance. New Phytol 191:480-495

Markesteijn L, Poorter L, Paz H, Sack L, Bongers F (2011 b) Ecological differentiation in xylem cavitation resistance is associated with stem and leaf structural traits. Plant Cell Environ 34:137-148

McDowell NG (2011) Mechanisms linking drought, hydraulics, carbon metabolism, and vegetation mortality. Plant Physiol 155:1051-1059

McElrone AJ, Pockman WT, Martinez-Vilalta J, Jackson RB (2004) Variation in xylem structure and function in stems and roots of trees to $20 \mathrm{~m}$ depth. New Phytol 163:507-517
Meinzer FC, James SA, Goldstein G (2004) Dynamics of transpiration, sap flow and use of stored water in tropical forest canopy trees. Tree Physiol 24:901-909

Nardini A, Salleo S (2000) Limitation of stomatal conductance by hydraulic traits: sensing or preventing xylem cavitation? Trees-Struct Funct 15:14-24

Nardini A, Salleo S, Raimondo F (2003) Changes in leaf hydraulic conductance correlate with leaf vein embolism in Cercis siliquastrum L. Trees-Struct Funct 17:529-534

O'Brien MJ, Engelbrecht BMJ, Joswig J, Pereyra G, Schuldt B, Jansen S, Kattge J, Landhausser SM, Levick SR, Preisler Y, Vaananen P, Macinnis-Ng C (2017) A synthesis of tree functional traits related to drought-induced mortality in forests across climatic-zones. J Appl Ecol 54:1669-1686

Ogaya R, Penuelas J, Asensio D, Llusia J (2011) Chlorophyll fluorescence responses to temperature and water availability in two co-dominant Mediterranean shrub and tree species in a long-term field experiment simulating climate change. Environ Exp Bot 73:89-93

Oren R, Sperry JS, Katul GG, Pataki DE, Ewers BE, Phillips N, Schafer KVR (1999) Survey and synthesis of intra- and interspecific variation in stomatal sensitivity to vapour pressure deficit. Plant Cell Environ 22:1515-1526

Pammenter NW, Vander Willigen C (1998) A mathematical and statistical analysis of the curves illustrating vulnerability of xylem to cavitation. Tree Physiol 18: 589-593

Pockman WT, Sperry JS (2000) Vulnerability to xylem cavitation and the distribution of Sonoran desert vegetation. Am J Bot 87:1287-1299

Pratt RB, Jacobsen AL, North GB, Sack L, Schenk HJ (2008) Plant hydraulics: new discoveries in the pipeline. New Phytol 179:590-593

Santiago LS, Goldstein G, Meinzer FC, Fisher JB, Machado K, Woodruff D, Jones T (2004) Leaf photosynthetic traits scale with hydraulic conductivity and wood density in Panamanian forest canopy trees. Oecologia 140:543-550

Sobrado MA (1993) Trade-off between water transport efficiency and leaf lifespan in a tropical dry forest. Oecologia 96:19-23

Sperry JS (2000) Hydraulic constraints on plant gas exchange. Agric For Meteorol 104:13-23

Sperry JS, Alder NN, Eastlack SE (1993) The effect of reduced hydraulic conductance on stomatal conductance and xylem cavitation. J Exp Bot 44: 1075-1082

Sperry JS, Nichols KL, Sullivan JE, Eastlack SE (1994) Xylem embolism in ringporous, diffuse-porous, and coniferous trees of northern Utah and interior Alaska. Ecology 75:1736-1752

Sperry JS, Saliendra NZ (1994) Intra-plant and inter-plant variation in xylem cavitation in Betula occidentalis. Plant Cell Environ 17:1233-1241

Tognetti R, Longobucco A, Raschi A (1998) Vulnerability of xylem to embolism in relation to plant hydraulic resistance in Quercus pubescens and Quercus ilex co-occurring in a Mediterranean coppice stand in Central Italy. New Phytol 139:437-447

Williams LJ, Bunyavejchewin S, Baker PJ (2008) Deciduousness in a seasonal tropical forest in western Thailand: interannual and intraspecific variation in timing, duration and environmental cues. Oecologia 155:571-582

Woodruff DR, McCulloh KA, Warren JM, Meinzer FC, Lachenbruch B (2007) Impacts of tree height on leaf hydraulic architecture and stomatal control in Douglas fir. Plant Cell Environ 30:559-569

Wu JM, Tong BQ, Yang J (2003) The relationship between climate of karst region in Guizhou Province and ecological administration. J Guizhou Meterol 5:25-28

Xiong D, Douthe C, Flexas J (2018) Differential coordination of stomatal conductance, mesophyll conductance, and leaf hydraulic conductance in response to changing light across species. Plant Cell Environ 41:436-450

Yu LF, Zhu SQ, Ye JZ (2002) Preliminary study on the adaptability of toleratedrought for different species group in karst forest. J Nanjing For Univ 26:19-22 